\title{
Raising Public Recognition of Climate Change Adaptation to Ensure Food Safety
}

\author{
Sun-Duk Cho, Hwa Jung Lee', and Gun-Hee Kim* \\ Department of Food \& Nutrition, Duksung Women's University, 419 Ssangmun-dong, Tobong-ku, Seoul 132-714, Korea \\ ${ }^{1}$ Food Safety Evaluation Department, National Institute of Food and Drug Safety Evaluation, Ministry of Food and \\ Drug Safety, Osongsaengmyeong2-ro, Osong-eup, Cheongwon-gun, Chungcheongbuk-do 363-700, Korea
}

(Received January 29, 2013/Revised July 15, 2013/Accepted September 3, 2013)

\begin{abstract}
Recent changes in the global climate environment have resulted in a wide variety of climaterelated disasters, including floods, tidal waves, forest fires, droughts, etc. In addition, global warming raises the risk of food poisoning, which may increase the spread of infectious diseases and alter their structure. Under these circumstances, it is necessary to provide accurate and persuasive information to consumers so that they can be fully informed of climate change and alter their behavior accordingly. Therefore, the intention of this study was to develop posters and contents for image production related to climate change and food safety. The posters are focused on consumers with headings such as ${ }^{\mathbb{C}}$ Climate Change Threatening Food Safety』, ${ }^{\circledR}$ Earth getting warmer, your dining table is at risk』, ${ }^{\mathbb{W}}$ Warning signs ahead for the globe $\_$, and more. Five poster drafts were selected initially, and a survey was carried out amongst 1,087 people regarding their preferences, with the most preferred design chosen. The images related to climate change and food safety defined climate change, how it relates to food safety, the risks it poses to the food industry, and lastly, how the public can respond in the future. Therefore, to further communicate the importance of food safety to consumers, the development, education, and promotion of these contents should be performed to provide safety information to consumers in the future.
\end{abstract}

Key words: climate change, food safety, consumer, public information, education

Climate is commonly defined as the weather averaged over a long time period. The climate of a particular area also includes weather-related statistics other than just average temperature, such as the magnitudes of day-to-day or year-toyear variations. Specifically, global warming results in an abnormal global climate, causing disasters all over the world. Serious climate change can cause diseases, flooding, drought, famine, a decrease in the variety of animal species, and melting of glaciers, all of which can lead to a grave threat to humans ${ }^{1,2)}$. The Intergovernmental Panel on Climate Change (IPCC) defines climate as follows: Climate, in a narrow sense, is usually defined as the "average weather," or more rigorously, as a statistical description in terms of the mean and variability of relevant quantities over a time period ranging from months to thousands or millions of years. An abnormal climate includes all sorts of climate changes that occur over time, regardless of whether or not they are caused

\footnotetext{
*Correspondence to: Gun-Hee Kim, Dept. of Food \& Nutrition, DukSung Women's University 419 SsangMun-Dong, ToBong-Ku, Seoul 132-714, Korea

Tel: 82-2-901-8496, Fax: 82-2-901-8474

E-mail: ghkim@duksung.ac.kr
}

naturally or by humans. The IPCC reported in the 4th Report (2007) that global warming is an obvious fact, with the probability that global warming is caused by external factors, including human activities, being $95 \%$ or higher ${ }^{3}$.

According to the Korea Meteorological Administration, the temperature of Korea has risen $1.7^{\circ} \mathrm{C}$ over the past 100 years (since 1904), and it is predicted that the temperature of Korea will increase further by about $3^{\circ} \mathrm{C}$, whereas the annual level of rainfall will increase by around $15 \%$ by $2100^{4)}$. Further, climate change will likely result in higher frequency of human maladies such as infectious diseases, malnutrition, and heart-related illness as well as natural disasters such as heat waves, flooding, and drought. As evidence of this, diseases that are mainly associated with tropical and subtropical zones such as malaria, dengue fever, West Nile fever, and Japanese encephalitis are currently spreading to mid-latitude areas ${ }^{5)}$. Further, changes in temperature, humidity, and rainfall due to global warming have effects on food production, causing problems related to food security. Thus, countermeasures on the national as well as worldwide levels are required to address this pending food safety problem ${ }^{6,7)}$.

The idea that climate change could become the most 
serious threat ever to humans has already been depicted in popular culture, including movies and fiction. However, currently, there is hardly any concern about how such climate change could affect our everyday lives. Nevertheless, since the problem of climate change has a potentially gigantic ripple effect, humans must take appropriate countermeasures. For example, climate change directly and indirectly affects not only crop production, but also the production, transport, and storage environments of all foods ${ }^{8)}$. Therefore, changes in such climate-related factors as temperature, relative humidity, and rainfall could bring about the occurrence of fungi on foods and subsequently production of fungal toxins, which constitute a serious threat to the health of humans and animals ${ }^{9)}$. Those foods potentially affected by climate change include fresh fruits and vegetables as well as marine products related to water pollution ${ }^{10)}$.

Countermeasures to climate change are largely divided into mitigation measure and adaptation measure. Specifically, reduction of the magnitude of future climate change is termed mitigation. Therefore, mitigation measure involves the prevention of further climate change by decreasing the emission of greenhouse gases that cause global warming or by amplifying absorbing sources of greenhouse gases. Other policy responses include adaptation to climate change. Adaptation measure means minimizing the expected effects of climate change by constraining the ripple effect or by exploiting the expected effects as new chances ${ }^{11)}$. The IPCC defines adaptation as "an activity that reduces the harm occurring from the ripple effect and impact of climate change that occur currently or are predicted to occur in the future, or further, an activity that facilitates the harm to be used as a useful chance through natural and man-made system control." After all, adaptation measure is both a controlling process that minimizes the ongoing effects of climate change as well as a process that enhances the capability of humans to cope with extreme climate phenomena ${ }^{12)}$.

Global warming increases the risk of food poisoning and the occurrence and patterns of infectious diseases ${ }^{13)}$. In this situation, it has been suggested that more accurate and persuasive information on climate change be provided to the public for the purpose of fully informing consumers so as to induce changes in behavior. Providing consumers with precise information on the safety of foods and promoting and educating them on related knowledge should be treated as one of the key elements of food safety policies. The government therefore develops a variety of consumer education/promotion methods concerning the safety of food, and provides necessary information through its homepage, leaflets, and other sources. Thus, this study attempted to develop contents for the production of posters and images in order to increase awareness of food safety, since food poisoning can occur during food handling, processing, storage, distribution, and consumption.

\section{Materials and Methods}

\section{Poster production}

Increases in temperature and water shortage caused by climate change can result in the development of various zoonoses, production of mycotoxins, and pollution such as antibiotic residues. These factors may also cause food poisoning during food handling, processing, storage, distribution, and consumption. Accordingly, this study developed posters to promote awareness of the food poisoning problem. These posters will be distributed to consumers, and the key words in these posters include climate change and food safety. The posters are focused on consumers with headings such as ${ }^{『}$ Climate Change Threatening Food Safety』, ${ }^{\circledR}$ Earth getting warmer, your dining table is at risk $\_$, ${ }^{\circledR}$ Warning signs ahead for the globe $₫$, and more. The body of the posters contain the following: ГTemperature and humidity increases according to climate change activate fungi and poisons. These fungi and poisons contain carcinogens and can cause various diseases such as food poisoning. Thus, foods polluted with fungal toxins must be discarded, with even small bites being avoided. Our dietary lives are now threatened by diseases caused by climate change. $\lrcorner^{14,15)}$.

A total of 1,087 people were surveyed regarding their poster preferences in order to select a poster design that can most effectively deliver the definitions of climate change and food safety. First, 675 people were surveyed during the Bio Korea 2010 Conference \& Exhibition period as the 1st survey (9.1 3) in 2010, and later, 412 people including the employees of the Ministry of Food and Drug Safety were surveyed regarding their poster preferences as the 2 nd survey (9.16). The final adopted poster consisted of five drafts selected among the proposed drafts through a professional advisory committee (Fig. 1).

\section{Production of promotion image contents}

Analysis of educational data was attempted through overseas/domestic websites and professional literature related to climate change and food safety, and information required for consumers were collected. The selected education curriculum allowed consumers to become aware of and cope with the symptoms and effects of infectious diseases, food poisoning, marine products, agricultural and stockbreeding products, and agrochemicals that occur in response to climate change.

As a result, information that is at the consumers' level of understanding but still scientifically accurate could be provided. The image contents were modified and supplemented 

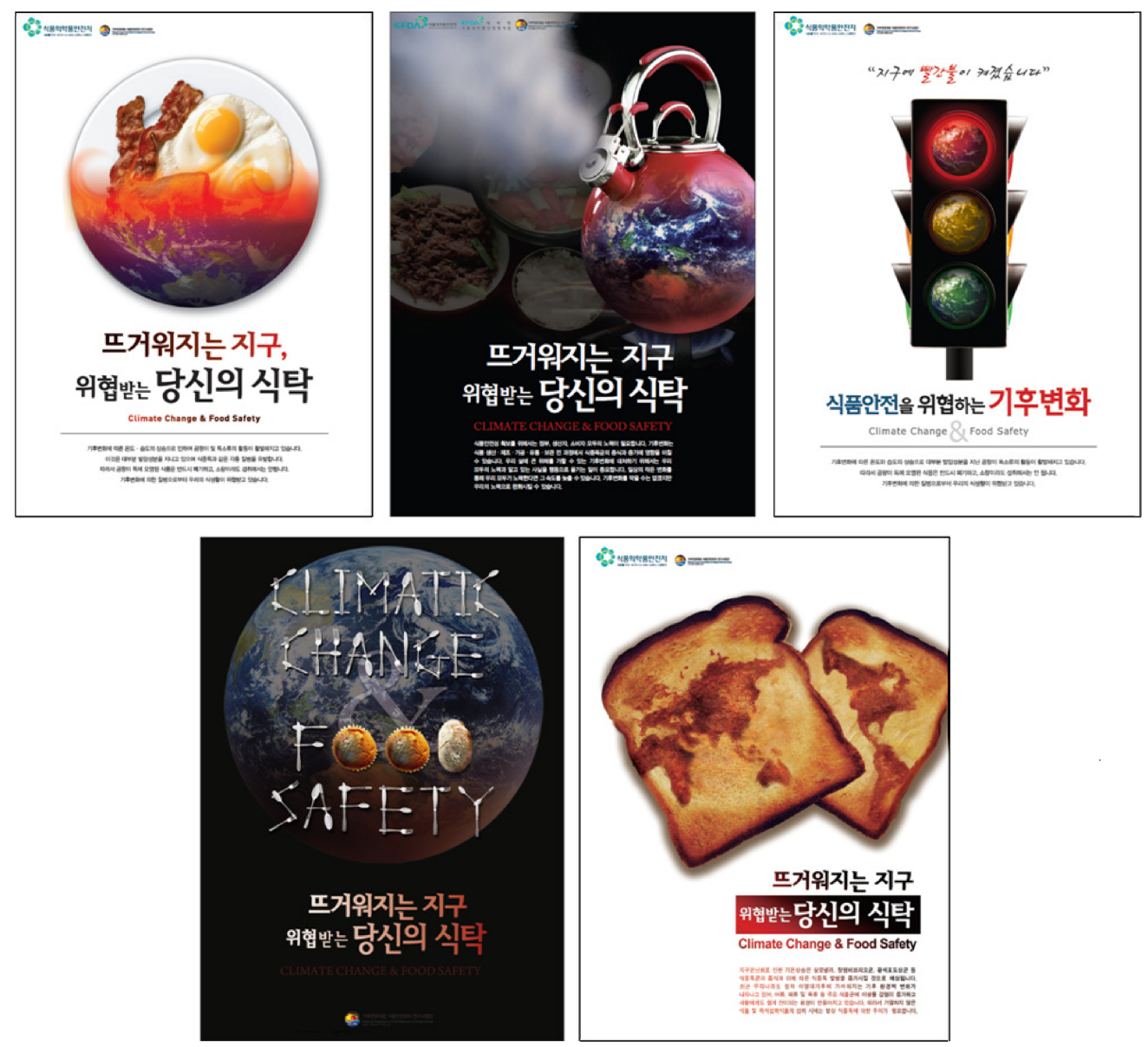

Fig. 1. Draft poster designs.

based on the evaluations of the advisory committee, which consisted of persons from the government, academia, and consumers. The Advisory Committee consisted of 10 professionals from the Research Group on Food Safety Control against Climate Change, consumer organizations, the Ministry of Food and Drug Safety, among other entities. Various tables and graphs produced based on objective materials and statistics were used, and while the use of terminologies was minimized, universal and easy contents were used to comprise the image material. The title of the image material is Climate Change and Food Safety, and the contents are largely divided into three parts. The early part consists of a general description of climate change while the middle part gives information on food safety problems caused by climate change. The final part explains methods that can be practiced in a simple way (Table 1).

\section{Results and Discussion}

\section{Poster production}

The results of the preference survey that was conducted on the five poster drafts on climate change and food safety

Table 1. Basic scenario of promotional image about climate change and food safety

\begin{tabular}{|c|c|}
\hline & Contents \\
\hline Prologue & Shows how environment is rapidly changing according to climate change and gives risks of climate change that threaten food safety. \\
\hline Title & Climate change and food safety \\
\hline Body 1 & $\begin{array}{l}\text { Effects of climate changes worldwide. } \\
\text { Importance of food safety management according to climate change. }\end{array}$ \\
\hline Body 2 & Impact of climate change on food \\
\hline Body 3 & More effort is urged to cope with climate change \\
\hline Epilogue & $\begin{array}{l}\text { The best gift for the next generation is not to pass on disasters brought about by climate change, and food safety management } \\
\text { according to climate change is a task that should be studied to prevent the problems with food safety. }\end{array}$ \\
\hline
\end{tabular}




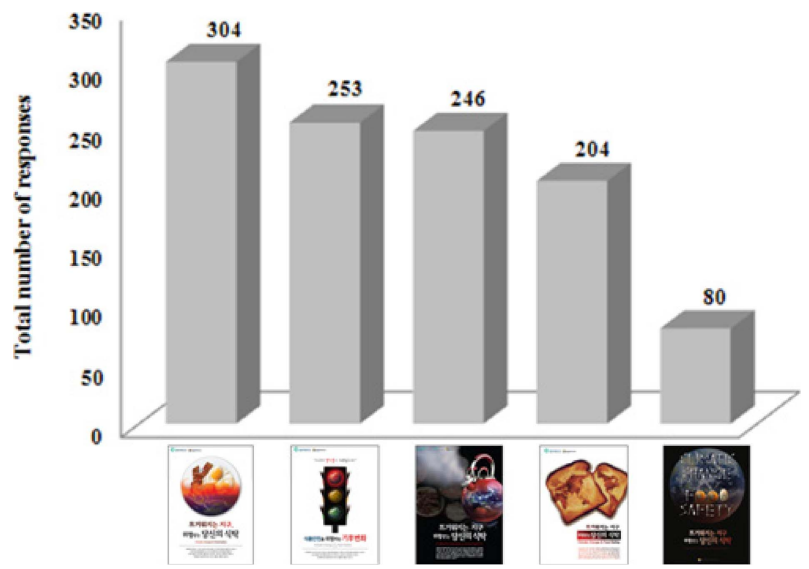

Fig. 2. Survey of preference for $\lceil$ Climate Change \& Food Safety $\lrcorner$ poster.

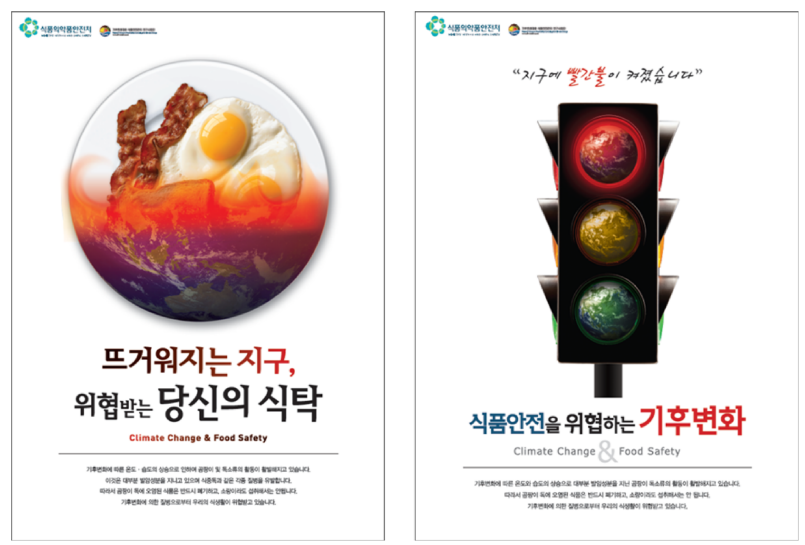

Fig. 3. Final draft poster images (size; $59.4 * 84.1 \mathrm{~cm}$ ).

are as shown in Fig. 2. The preference for the poster draft represented with plates, eggs, and bacon was $27.97 \%$, which was the highest. The preference for the draft featuring the signal light illustration was $23.28 \%$, whereas the preference for the draft featuring the kettle illustration was $22.63 \%$, both of which are similar values. And then, the preference for the draft that represented the Earth with a blackened bread was $18.77 \%$. Finally, the preference for the draft that represented the Earth with spoons and forks was $7.36 \%$, the lowest. Finally, two complete posters were produced based on the above poster preference survey results (Fig. 3).

\section{Production of promotion image contents}

Climate change can cause weather-related damages such as flood and drought in the short term, resulting in enormous economic losses in the long term, thereby putting the safety and health of human society at risk. Thus, countermeasures against climate change are desperately required. Moreover, additional adaptation measures against the effects of climate change that will occur in the future are needed. Consistent adaptation measures to climate change can not only decrease socioeconomic damage but also bring about industrial benefits ${ }^{16)}$. Adaptation and appeasement measures for coping with climate change are necessary and complementary, and although adaptation to climate change requires economic costs, preventive adaptation can decrease the vulnerability of humans to the effects of climate change ${ }^{17)}$.

Since the main causes of climate change are mostly attributable to human consumption, it is critical to target consumers ${ }^{3)}$. Inducing behavioral changes in consumers is a very difficult process, but it is necessary and must be conducted. The most comprehensive and basic method for this is persuasion through education. This study developed image contents under the title $\ulcorner$ Climate Change \& Food Safety $\lrcorner$ in order to produce promotional images related to the effects of climate change on food safety.

Through this image material, this study offers several answers to questions related to climate change, such as 'What is the problem?', 'What do we know?', and 'How can we adapt?' This study used somewhat stimulating images that make the association between climate change and food safety. Easy narrations and images that can be easily understood by the general public were developed in order to increase awareness of climate change. In addition, images and factual graphics to increase awareness of the crisis were added to the promotional images so that the information could be more effectively delivered. Various risk factors that are caused by climate change and that can affect daily human life were explained carefully. The introduction part of the image material explains environmental changes in response to climate change as well as harmful effects. The $\ulcorner$ Monster Created by Humans, Climate Change $\lrcorner$ consists of contents that emphasize the seriousness of climate change. The $\ulcorner$ Inconvenient Change Brought About by Climate Change $\lrcorner$ describes the harmful effects on each food sector, and $\ulcorner$ Risky Truth of Food Safety Due to Climate Changes $\lrcorner$ explains how climate change affect food safety. Finally, 「Our Effort to Cope to Climate Changes」 shows what humans have to do in the future.

What are some simple methods through which we can cope with climate change in our daily lives?

- Go on foot or use public transport when moving short distances.

-When purchasing an electric appliance, select the product ranked 1st in energy consumption efficiency.

- When using the air conditioner or heater, maintain an appropriate indoor temperature.

- As for food, establish a dietary plan to purchase only necessary items.

- Use in-season foods that are produced in your own province or area. 

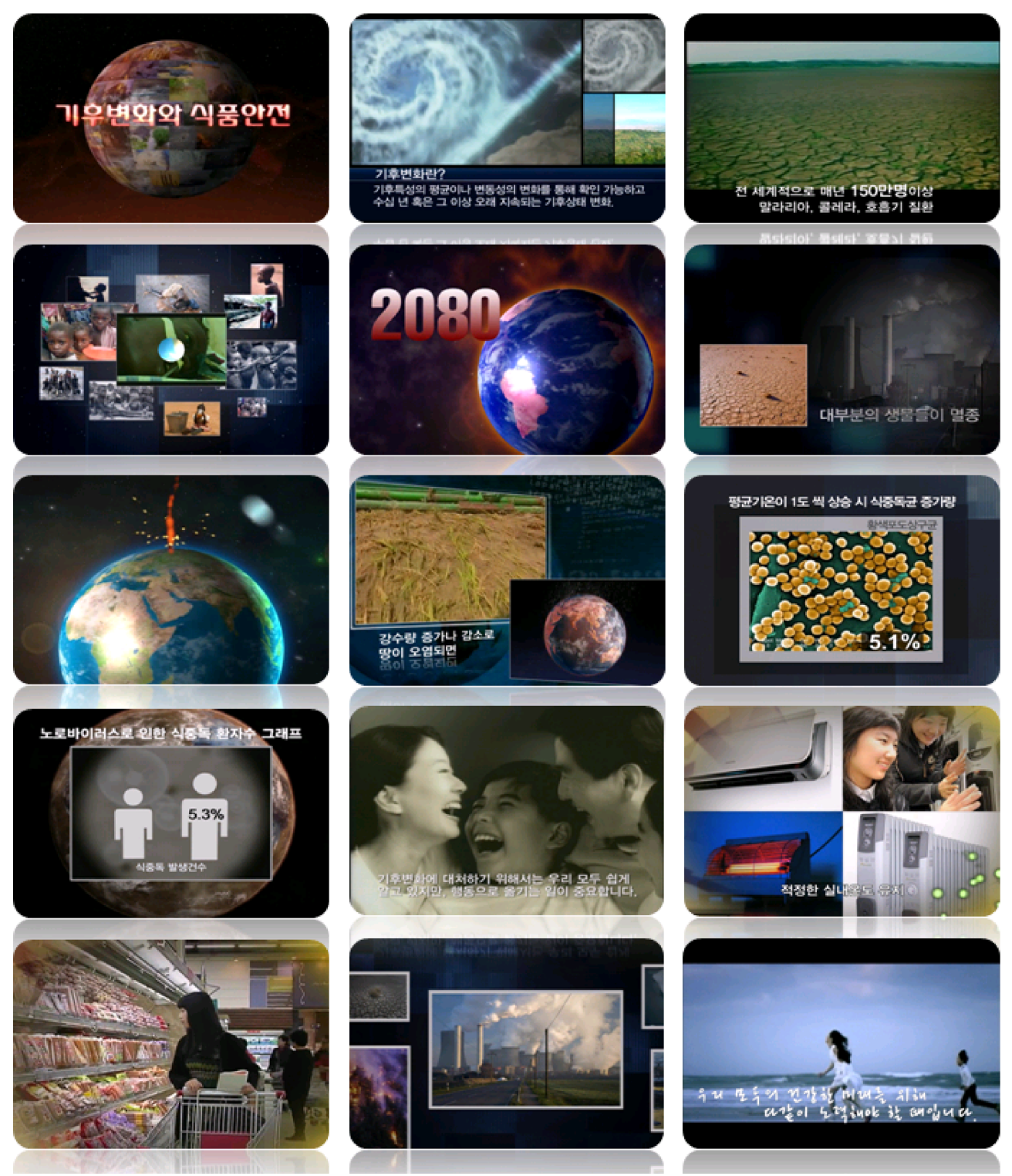

Fig. 4. The still cut from video "Climate Change \& Food Safety" (Target; consumer, Running time; 10 min).

- After purchasing foods, check and maintain the appropriate storage temperature.

- When storing foods in the refrigerator, arrange them in a way that makes them visible.

- Fill the refrigerator to only $70 \%$ so that cool air can circulate well.

\section{Conclusion}

The problems associated with climate change are no longer events that will occur far in the distant future. Only if all humans make an effort to change their behavior in their daily lives can the effects of global warming be delayed. Although climate change cannot be prevented completely, its negative effects can be reduced with sincere effort. This will make it possible to resolve generalized anxiety over food through the provision of information on climate change and food safety, and it will be necessary to develop safety information content to regularly provide to consumers and reinforce the education/promotion to expand channels of communication for food safety with consumers in the future.

\section{Acknowledgements}

This research was support by a grant (10162MFDS995) from Ministry of Food and Drug Safety in 2010.

\section{References}

1. Isaacson, R.E., Torrence, M., and Buckley, M.R.: Preharvest 
food safety and security. American Society for Microbiology. Washington D.C. Available at http://www.asm.org/Academy/ index.asp?bid=33019. (2004).

2. Shin, I.C., and Kim Y.S.: A policy suggestion for the adaptation of climate change in Korea. Atmosphere, 19, 53-66 (2009).

3. IPCC. Climate change 2007: Impacts, adaption and vulnerability, Fourth Assessment Report, Cambridge University Press, Cambridge, UK. (2007).

4. Chae, J.S.: Impact of climate change on pathogens, vectors, reservoirs and hosts in Korea. Korean Journal of Veterinary Science, 50, 35-40 (2010).

5. Houghton, J.: Global warming. Reports on Progress in Physics, 68, 1343-1403 (2005).

6. Cha, M.H., Yang, J.H., Oh, S.W., Lee, H.J., Kim, D.S., Chung, M.S., and Ryu, K.: Food emergency response plan towards climate change. Safe Food, 5, 19-26 (2010).

7. Kim, Y.S.: A survey on climate change and food safety. Safe Food, 4, 19-23 (2009).

8. FAO.: Global Information and Early Warning System on Food and Agriculture (GIEWS). Food and Agriculture Organization, Rome. Available at http://www.fao.org/GIEWS/english/ index.htm. (2008).

9. Kim, D.M., and Chun, H.S.: Influence of the climate change on growth of fungi and mycotoxin production. Food Science and Industry, 42, 27-35 (2009).

10. Seo, K.H.: The impacts of climate change on the food-borne disease. Korean Journal of Veterinary Science, 50, 65-66 (2010).

11. Koh, J.K., Choi, C.K., and Kim, H.S.: A study on adapting to climate change in local governments - focusing on natural disasters - Korean Journal of Regional Development, 22, 6786 (2010).

12. Lee, J.W.: The case study of adaptation modeling for climate change hazard in developed countries. Korean Journal of Professional Geographers, 44, 213-227 (2010).

13. Chung, M.S.: Food safety management and climate change. Safe Food, 4, 11-18 (2009).

14. Kovats, R.S., Edwards, W.J., Haja, S., Armstrong, B.G., Ebi, K.L., and Menne, B.: The effect of temperature on food poisoning: a time-series analysis of salmonellosis in the European countries. Epidemiology and Infection, 132, 1-10 (2004).

15. Parry, M.L., Rosenzweig, C., Iglesias, A., Livermore, M., and Fischer, G.: Effects of climate change on global food production under SRES emissions and socio-economic scenarios, Global Environmental Change, 14, 53-67 (2004).

16. Kwon, W.T.: Current status and perspectives of climate change sciences. Korean Journal of the Atmospheric Science, 41, 325336 (2005).

17. Easterling, W.E., Hurd, B.H., and Smith, J.B.: Coping with global climate change: The role of adaptation in the United States. Pew Center Report, pp 36 (2004). 